\title{
A NECESSIDADE DA RELEITURA DA AÇÃO EDUCATIVA PRESENTE NA EDUCAÇÃO AMBIENTAL COMO PRÉ REQUISITO AO ALCANCE DO MEIO AMBIENTE ECOLOGICAMENTE EQUILIBRADO
}

\author{
Vânia Ágda de Oliveira Carvalho ${ }^{1}$ \\ Émilien Villas Boas Reis ${ }^{2}$
}

\section{RESUMO}

Para que se possa utilizar o meio ambiente sem extinguir seus recursos é preciso que os cidadãos formem consciência ecológica crítica, e, nesse viés, está a educação ambiental. Contudo, com base na normatividade de tal instrumento e visando sua eficácia, nota-se a necessidade de releitura da ação educativa presente nos pilares da educação ambiental, sendo esse, o escopo do presente artigo. Concluir-se-á que os fundamentos da Paideia junto à análise dos pilares para além do ambiental corroboram para a releitura da ação aqui proposta. O método usado foi o teórico-jurídico com raciocínio dedutivo e técnica de pesquisa bibliográfica.

Palavras chave: Meio ambiente; Educação ambiental; Normatividade; Ação educativa; Desenvolvimento sustentável

THE NEED FOR THE RELEASE OF THE EDUCATIONAL ACTION PRESENT IN ENVIRONMENTAL EDUCATION AS A PREREQUISITE TO THE REACH OF THE ECOLOGICALLY BALANCED ENVIRONMENT

\begin{abstract}
In to be able to use the environment without extinguishing its resources, it is necessary that citizens form critical ecological awareness, and, in this bias, there is environmental education. However, based on the your normativity and aiming for its effectiveness, it is necessary to reread the educational action present in the environmental education, the scope of this article. It will be concluded that the foundations of Paideia together with the analysis of the pillars

\footnotetext{
${ }^{1}$ Mestranda em Direito Ambiental e Desenvolvimento Sustentável - Dom Helder Câmara/MG. Especialista em Civil e Processo Civil - FADIVALE/MG. Currículo Lattes: http://lattes.cnpq.br/0769658610006569. E-mail: vaniaagdaocarvalho@gmail.com

${ }^{2}$ Pós-doutor em Filosofia - FLUP/Portugal. Doutor e Mestre em Filosofia - PUCRS. Graduado em Filosofia pela UFMG- BH/MG. Professor de Filosofia e Filosofia do Direito na graduação e no mestrado da Escola Superior Dom Helder Câmara -BH/MG.
}

Revista de Pesquisa e Educação Jurídica | e-ISSN: 2525-9636 | Brasília | v. 3 | n. 1 | p. 22-43 | Jan/Jul. 2017. 
beyond the environmental corroborate for the re-reading of the action proposed here. The method used was the theoretical-juridical with deductive reasoning and bibliographic research technique.

Keywords: Environment; Environmental education; Normativity; Educational action; Sustainable development

\section{INTRODUÇÃO}

Hodiernamente, diante da realidade degradatória ambiental, urge uma necessidade de providências no sentido de viabilizar meios para estagnar ou minimizar os impactos negativos sobre a natureza, com intuito de evitar a extinção da própria espécie humana.

Nesse sentido, a educação ambiental aparece como um dos meios a auxiliar as ferramentas de preservação da natureza, podendo ser analisada como meio inerente à construção da verdadeira cidadania.

Consciência ecológica crítica, pautada em um desenvolvimento sustentável, para que se possa desfrutar do meio ambiente sem extinguir seus recursos, é escopo da educação ambiental. Ademais, ao tornar obrigatória a sua promoção, a Constituição da República Federativa do Brasil de 1988 (CRFB/1988) orienta-se pela suposição de que para defender e preservar o meio ambiente não basta o uso de mecanismos de sanção e de promoção do direito, sendo necessário promover a educação e a conscientização pública.

Entretanto, a forma como a educação ambiental vem sendo difundida, não conduz para sua efetividade. É necessária uma releitura do processo consubstanciado na ação educativa, engendrada no ato de educar, com observância na forma como o conhecimento é repassado, salientando a abordagem da complexidade ambiental, em prol de tornar a educação ambiental eficaz e, com isso, atingir o seu propósito, qual seja, disseminar a necessidade em se preservar o meio ambiente, conforme preceitos constitucionais.

No que se refere ao ensino jurídico, não é mais cabível inércia concernente à educação ambiental, não apenas por sua previsão na CRFB/1988, mas por todo alicerce que a vincula à formação de cidadãos, viabilizando processos participativos em prol das problemáticas socioambientais. 
Assim, o presente artigo possui, como objetivo geral, verificar a necessidade de uma releitura da ação educativa consubstanciada na educação ambiental. Quanto ao objetivo específico, analisar a ação educativa presente na educação ambiental na perspectiva traçada na Paideia $(\pi \alpha 1 \delta \varepsilon i ́ \alpha)$, a analisando também em uma abordagem do ensino jurídico. Ou seja, destinar à educação ambiental um viés de educação permanente e continuada, considerando a complexidade ambiental, com a relevância em se destacar os pilares sociais e econômicos no destrinchar da educação ambiental.

Esse artigo seguirá uma linha de exposição em três grandes itens. No primeiro será analisada a educação ambiental como instrumento para disseminar a necessidade da preservação do meio ambiente, apresentando sua previsão constitucional. No segundo item ocorrerá abordagem quanto à efetivação da educação ambiental, traçando abordagens relativas à sua normatividade. No terceiro item será apresentada a necessidade de uma releitura da ação educativa consubstanciada na educação ambiental, com intuito de torná-la um instrumento mais eficaz em prol da preservação ambiental, evidenciando-a, inclusive, como instrumento emancipatório.

Após o desenrolar dos itens, serão apresentadas as considerações finais que se alcançaram com o desenvolver do tema.

Para o desenvolvimento desse artigo, será adotado o método teórico-jurídico com raciocínio dedutivo e técnica de pesquisa bibliográfica.

\section{A PRESERVAÇÃO DO MEIO AMBIENTE DISSEMINADA POR MEIO DA EDUCAÇÃO AMBIENTAL}

Com as mudanças ocorridas no transcurso da história e com a supervalorização do acúmulo de riquezas, especialmente com o advento da Revolução Industrial, o ser humano despertou-se por preceitos relevantes, como a preservação do meio ambiente, ou seja, a forma como se lidava com a apropriação dos meios naturais a inserir no meio de produção.

Nesse sentido, foi necessária a positivação da relação homem e natureza, inclusive, como meio de pertença e perpetuação da própria espécie humana. Condiz como o aludido:

[...] relação do homem com o meio ambiente é objeto de proteção específica pelo sistema positivo brasileiro. A CF/881, em seu artigo 225, é taxativa em afirmar que

Revista de Pesquisa e Educação Jurídica | e-ISSN: 2525-9636 | Brasília | v. 3 | n. 1 | p. 22-43 | Jan/Jul. 2017. 
a proteção do meio ambiente, direito das presentes e futuras gerações, insere-se no rol de direitos a serem protegidos pelo Estado [...] (BARRETO; MACHADO, 2016, p. 323).

Reconhecida e positivada a relação homem e natureza, viu-se então necessário abordar o tema preservação ambiental por meio de instrumentos que fossem capazes de criar consciência nos homens com intuito de alterar seu comportamento para com sua própria espécie, tendo em vista que, devastando a natureza e proporcionando seu fim, se auto expõem à extinção (COSTA, 2010).

Pondera-se, nesse prisma, o poder transformador da educação ambiental no sentido de disseminar a necessidade em se preservar o meio ambiente, tendo em vista, sobremaneira, as hodiernas catástrofes ocorridas.

Em um cenário mundial, a Conferência Intergovernamental sobre Educação Ambiental ocorrida em Tbilisi, Geórgia, em 1977, foi um marco revolucionário, no sentido de que recomendou aprofundamento da função, dos objetivos e das características da educação ambiental, vindo a esclarecer sua finalidade e princípios, oriundos da Declaração de Estocolmo (1972) e perpetrada na Carta de Belgrado (1975):

\begin{abstract}
A partir da Conferência Intergovernamental sobre Educação Ambiental realizada em Tsibilisi (EUA), em 1977, inicia-se um amplo processo em nível global orientado para criar as condições que formem uma nova consciência sobre o valor da natureza e para reorientar a produção de conhecimento baseada nos métodos da interdisciplinaridade e nos princípios da complexidade. Esse campo educativo tem sido fertilizado transversalmente, e isso tem possibilitado a realização de experiências concretas de educação ambiental de forma criativa e inovadora por diversos segmentos da população e em diversos níveis de formação. (JACOBI, 2003, p.190). (grifo nosso).
\end{abstract}

Dessa forma, incontroversa a inserção na sociedade atual da necessidade de preservação do meio ambiente, que se faz possível por meio de uma educação ambiental, posto a possibilidade de formar consciência ecológica crítica. Segundo Leff (2001), a educação ambiental é instrumento que estimula o avanço na construção de novos objetos interdisciplinares de estudo mediante questionamentos dos modelos dominantes e da incorporação do saber ambiental em novos programas curriculares, na consubstanciação da 
transdisciplinaridade, na formação de educadores e profissionais da área do meio ambiente, bem como norteadora de comportamentos individuais, alterando padrões no agir.

A partir do momento em que o indivíduo detém o conhecimento teórico e inicia a sua prática na preservação ambiental, está corroborando para a perpetuação de todo o ecossistema em que vive, possibilitando a qualidade de vida e, consequentemente, agindo em solidariedade, bem como os deveres a ela inerentes, tendo em vista a projeção em face das futuras gerações (Sarlet; Fenterseifer, 2011). Tem-se que essa atitude é condizente com o binômio poder/dever inerente ao vocábulo "todos", conforme preconiza o texto constitucional, em seu art 225, ao relatar acerca da responsabilidade sobre a defesa e preservação do meio ambiente.

Essa afirmação funda-se no destrinchar do conceito de cidadania, sobre o prisma de que ser cidadão é ter a consciência de que é sujeito de direitos, tais como à vida, ao meio ambiente equilibrado, à liberdade, igualdade, direitos políticos e sociais, bem como a implicação de ser agente detentor de deveres para com sua preservação.

Sendo, pois, o meio ambiente ecologicamente equilibrado um direito fundamental, a CRFB/1988 especificou deveres inerentes ao Poder Público para a sua efetividade e, dentre esses deveres está a promoção da educação ambiental.

\subsection{Previsão constitucional da educação ambiental}

A União introduziu no ordenamento jurídico brasileiro a Lei n. 9.795/99 que dispõe sobre a educação ambiental e institui a Política Nacional de Educação Ambiental, regulamentado pelo Decreto n. 4.281/02, como forma de efetivar o estipulado na CRFB/1988, no inciso VI, § 1. ${ }^{\circ}$, do art. 225: "promover a educação ambiental em todos os níveis de ensino e a conscientização pública para a preservação do meio ambiente” (BRASIL, 1988).

A partir do momento em que a CRFB/1988 torna obrigatório ao Poder Público realizar a educação ambiental, orienta-se, pois, pela suposição de que realmente não basta adotar um viés punitivo, mas, sim, vislumbrar mecanismos que orientem a população da necessidade em se preservar o meio, do qual, inclusive, é parte integrante o ser humano.

Revista de Pesquisa e Educação Jurídica | e-ISSN: 2525-9636 | Brasília | v. 3 | n. 1 | p. 22-43 | Jan/Jul. 2017. 
Realizando ampla análise constitucional, tem-se que a promoção da educação ambiental está intimamente ligada ao princípio da informação ${ }^{3}$, posto que por meio da educação forma-se e informa-se. A segunda parte do inciso $\mathrm{V}$ do art. $4^{\circ}$ determina que a Política Nacional do Meio Ambiente (Lei 6.938/1981) visará: "à divulgação de dados e informações ambientais e à formação de uma consciência pública sobre a necessidade de preservação da qualidade ambiental e do equilíbrio ecológico”. (BRASIL, 1981).

Assim, todo indivíduo pode requerer informação sobre qualquer assunto na área ambiental, adstrito ao órgão público a negativa somente em casos em que a empresa envolvida considerar sigilo industrial. É o que preconiza a Lei 10.650/03, combinada com a Lei citada acima, qual seja, Lei 12.527/2011.

Entretanto, para que as informações possibilitem aos interessados uma tangível atitude concernente à tutela ao meio ambiente, é necessário que os mesmos compreendam as questões pertinentes. Equivale afirmar a necessidade de educação ambiental, ou seja, como se verá à diante, de educação.

A Lei n. 9.795/99 define, no art. $1^{\circ}$, educação ambiental:

[...] os processos por meio dos quais o indivíduo e a coletividade constroem valores sociais, conhecimentos, habilidades, atitudes e competências voltadas para a conservação do meio ambiente, bem de uso comum do povo, essencial à sadia qualidade de vida e sua sustentabilidade. (BRASIL, 1999).

Nota-se, assim, conceito dinâmico da educação ambiental, não sendo, pois, concebida como conjunto estático de conhecimentos sobre o ambiente a serem transmitidos a alguém, que os recebe passivamente. Há um caráter de disseminação da informação, de aprendizagem contínua e duradoura, que se percebe, inclusive, nos objetivos contidos na Lei n. 9.795/99. Nesse viés:

\footnotetext{
${ }^{3}$ Nos ensinamentos de Sampaio, Wold e Nardy, "O direito à informação tem natureza coletiva e ocupa um lugar central nos Estados Democráticos. Quando a informação se refere à situação, disponibilidade e qualidade dos recursos naturais, bem como sobre políticas, medidas e decisões que tenham por objeto tais recursos, torna-se ainda importante a sua afirmação, não só para que todos tomem ciência do estado, das propostas e execuções de manejos de seu entorno natural, construindo e renovando uma 'opinião pública ambiental informada", mas sobretudo para que possam contribuir de maneira efetiva e consciente nos processos decisórios que venham a gerar efeitos sobre a natureza. (SAMPAIO; WOLD; NARDY, 2003, p. 76-77).
} 
A Lei n. 9.795/1999 enuncia, no art. $5^{\circ}$ os objetivos fundamentais da educação ambiental, em diversos artigos. Podem ser citados como objetivos: garantir a democratização das informações ambientais; incentivar a participação individual e coletiva, permanente e responsável, na preservação do equilíbrio do ambiente; o fortalecimento da cidadania, autodeterminação dos povos e a solidariedade como fundamentos para o futuro da humanidade. (FURLAN et al, 2010, p. 90).

Reforça a relevância da educação ambiental para assegurar a efetividade do direito ao ambiente ecologicamente equilibrado perpetrado no art. 225 da CRFB/1988, a Lei $n^{\circ}$ 9.795/1999, ao determinar que: “a educação ambiental é um componente essencial e permanente da educação nacional, devendo estar presente, de forma articulada, em todos os níveis e modalidades do processo educativo, em caráter formal e não-formal" (BRASIL, 1999, art. $2^{\circ}$ ).

Diante do trazido, em síntese, tem-se que ao ensino jurídico não é mais cabível inércia no que tange à educação ambiental, não apenas por sua previsão na CRFB/1988, mas por todo alicerce que a vincula à formação de cidadãos, viabilizando processos participativos em prol das problemáticas socioambientais.

Insta salientar que, apesar do arcabouço legal no que tange à educação ambiental, diante sua aplicabilidade, questiona-se sua real eficácia, destacando sua normatividade e a leitura do processo educativo inerente à mesma.

\section{EDUCAÇÃO AMBIENTAL E SUA EFETIVAÇÃO}

Nos ensinamentos de Gomes (2012), os atos administrativos normativos tornaram-se instrumentos da política educacional. No contexto da educação ambiental, diversos atos normativos, ligados ao Ministério do Meio Ambiente (MMA) e ao Ministério da Educação e Cultura (MEC) devem ser considerados e, para tal, observados os atos que os envolvem.

A educação ambiental no Brasil, segundo Leite e Medina (2001) se inicia de maneira oficial a partir da criação da Secretaria de Meio Ambiente (SEMA) no ano de 1973, vinculada ao Ministério do Interior, vindo a responder às exigências internacionais que emergiam à época, no quesito ambiental e suas necessidades.

Em 31 de agosto de 1981 é instituída a Lei nº 6.938/1981, a qual dispõe sobre a Política Nacional do Meio Ambiente, seus fins e mecanismos de formulação e aplicação, sendo que, em seu art. $7^{\circ}$, cria o Conselho Nacional do Meio Ambiente (CONAMA).

Revista de Pesquisa e Educação Jurídica | e-ISSN: 2525-9636 | Brasília | v. 3 | n. 1 | p. 22-43 | Jan/Jul. 2017. 
A CRFB/1988, em seu art. 225 também faz remissão à educação ambiental. Em 1994, é ocasionada a aquiescência do Programa Nacional de Educação Ambiental PRONEA, com a participação do MMA, MEC e do Instituto Brasileiro de Meio Ambiente e dos Recursos Naturais Renováveis (IBAMA). Contudo, somente em 1999, é instituída a Lei $\mathrm{n}^{\circ}$ 9.795/1999, a qual estabeleceu o PRONEA.

O Decreto $n^{0} 4.281 / 2002$ veio regulamentar a Lei $n^{0} 9.795 / 1999$, e criar o órgão gestor responsável pela coordenação da Política Nacional de Educação Ambiental, previsto no art. 14 da citada Lei $\mathrm{n}^{\circ} 9.795 / 1999$, instituindo, em seu art. $1^{\circ}$, que:

\footnotetext{
Art. $1^{\circ}$ do Decreto $n^{\circ}$ 4.281/2002. A Política Nacional de Educação Ambiental será executada pelos órgãos e entidades integrantes do Sistema Nacional de Meio Ambiente - SISNAMA, pelas instituições educacionais públicas e privadas dos sistemas de ensino, pelos órgãos públicos da União, Estados, Distrito Federal e Municípios, envolvendo entidades não governamentais, entidades de classe, meios de comunicação e demais segmentos da sociedade (BRASIL, 2002, art. $1^{\circ}$ ).
}

O MEC constrói, a partir das leis, pareceres e, da organização de atividades, a história da educação ambiental formal no Brasil. Serão relatados, dentre muitos, os principais atos administrativos normativos do MEC quanto à educação ambiental.

Em 1987, segundo Leite e Medina (2001) o MEC aprova, no que tange à imprescritibilidade em acrescentar a educação ambiental nos currículos escolares de $1^{\circ}$ e $2^{\circ}$ graus, o parecer 226/87 do conselho Arnaldo Niskier. Em 1988, iniciam-se as atividades da Coordenação de Educação Ambiental do MEC. Em 1991, o MEC lança a portaria 678, instituindo que todos os currículos contemplarão conteúdos de educação ambiental, considerando os variados níveis de ensino. Em 1993 há, com o escopo de originar e propagar metodologias destinadas à educação ambiental, a criação dos centros de educação ambiental do MEC.

Diante dos atos administrativos normativos citados acima, nota-se o Estado exercendo a sua função regulamentar (GOMES, 2012) no intuito em estabelecer critérios voltados para a educação ambiental, tanto no âmbito do MMA quanto do MEC. Todavia, pondera-se a respeito da efetivação da educação ambiental em especial o que tange ao estabelecido no art. 225 da CRFB/1988 e na Lei $n^{\circ}$ 9.795/1999, a qual institui a Política Nacional de Educação Ambiental após pouco mais de uma década de vigência. 
Steinmetz (2009) aduz que o problema quanto à real efetividade da Lei de educação ambiental não está tão somente no quesito da morosidade legislativa, tão evidenciada quando se observa que o Decreto regulamentador de lei foi editado três anos após a mesma. Segundo o autor (2009), também está presente em outros pontos, como por exemplo, na acessibilidade aos sites das secretarias estaduais e municipais do meio ambiente e da educação, que ademais, apresentam informações insuficientes e obsoletas quanto aos projetos de educação ambiental.

Steinmetz (2009) afirma ainda que, apesar de ser dever da coletividade defender e preservar o ambiente (art. 225, caput, CRFB/1988), as instituições privadas de ensino não destinam a devida atenção ao tema educação ambiental. Em que pese a Lei no 9.795/1999 incumbir às instituições educativas, em todos os níveis, de "[...] promover a educação ambiental de maneira integrada aos programas educacionais que desenvolvem" (BRASIL, 1999, art. $3^{\circ}$, inciso II) e instituir que a aprovação e supervisão para que as instituições de ensino e de seus cursos (tanto nas redes pública e privada) funcionem, devem observar o cumprimento das determinações da Lei $n^{\circ}$ 9.795/1999, para a educação ambiental no ensino formal (art. 12), tais requisitos não vêm sendo cumpridos.

Concernente a outros pontos da Lei no 9.795/1999 há, ainda, ponderações a serem realizadas, tendo em vista sua real efetividade. Exemplo plausível consiste no questionamento da opção legislativa de proibir a inserção da educação ambiental como disciplina singular no currículo de ensino, conforme art. $10, \S 1^{\circ}$.

Nesse prisma, para Steinmetz, a Lei de Educação Ambiental não é legislação simbólica, tendo em vista seu caráter de lei como normas gerais, a qual veicula mais diretrizes vagas. "Contudo, pode-se afirmar que o grau de efetividade da lei é baixo, muito aquém do razoável, após 10 anos de vigência” (STEINMETZ, 2009, p. 7).

Nas instituições de ensino superior (IES) não são constatadas atividades de pleno exercício quanto à educação ambiental, notando-se a restrita iniciativa de professores e alunos, normalmente, direcionada para "pesquisa sobre educação ambiental como linha de pesquisa ou projeto de pesquisa, seja por meio de programas ou projetos setoriais ou pontuais de educação ambiental” (STEINMETZ, 2009, p. 5).

Situação deflagrada também nas instituições de ensino jurídico, onde o modelo de ensino ainda "é permeado de processos tradicionais e repetidores de posições hegemônicas 
que evidenciam a reprodução de um modelo que pretende replicar o poder e manter o direito num âmbito de mero validador do sistema.” (ALVES; MACHADO, 2016, p. 72).

Loureiro aduz que, no campo do debate ambiental há um senso comum generalizado, de pouca profundidade, voltado para os conceitos, ocasionando o real motivo discursivo com o que se deseja e o que se deve fazer no campo educativo "ecológico, cidadão e crítico" (LOUREIRO, 2012, p. 24).

Nesse viés de se questionar a eficácia da normatividade da Lei de educação ambiental, bem como ponderar acerca dos critérios abordados pela mesma, não se pode olvidar a característica programática de referida legislação. Entretanto, como salienta Sarlet (2012), em que pese tratarem-se as normas programáticas de normas que apresentam normatividade insuficiente para alcançarem plena eficácia, "porquanto se tratam de normas que estabelecem programas, finalidade e tarefas a serem implementadas pelo Estado, ou que contêm determinadas imposições de maior ou menor concretude dirigidas ao Legislador" (SARLET, 2012, p. 292), as mesmas devem ser obrigatoriamente instituídas, tendo em vista sua eficácia como autênticas normas jurídicas.

Ademais, por se tratar de princípio, a educação ambiental apresenta extrema relevância no ordenamento jurídico, devendo ser sopesado fatidicamente sem existir qualquer hierarquia entre os demais princípios, convivendo harmonicamente no ordenamento jurídico.

Em suma, o Poder Público e os entes privados não levam a sério o princípio constitucional da educação ambiental enquanto mandamento direcionador das atividades voltadas para o alcance do meio ambiente ecologicamente equilibrado.

\section{UMA RELEITURA DA AÇÃO EDUCATIVA CONSUBSTANCIADA NA EDUCAÇÃO AMBIENTAL}

A educação ambiental atua como instrumento de viabilização pelo qual procura modificar a consciência humana, perpetrando comportamentos desejáveis. Entretanto, como já sabido, a educação ambiental formal ainda é um ideal desejado e a normatividade da Lei de educação ambiental é questionável, conforme apresentado.

Em que pese a educação ambiental não formal estar sendo observada como coadjuvante no papel da educação destinada ao meio ambiente, tendo em vista que a formal 
ainda encontra muitos entraves, tal afirmativa não prospera. Ambas podem e devem caminhar juntas para efetividade do direito ao meio ambiente ecologicamente equilibrado.

Apesar da educação ambiental não ser direito fundamental consagrado no texto da CRFB/1988, é princípio e apresenta extrema relevância no ordenamento jurídico pátrio, como já relatado. Ademais, encontra-se vinculado ao direito fundamental da educação e é instrumento de alcance do direito fundamental ao meio ambiente ecologicamente equilibrado, além de se encontrar intimamente ligado aos princípios da informação e da participação, tão inerentes ao Estado Democrático de Direito.

Ao se considerar que as normas de proteção ao meio ambiente não se destinam necessariamente a modificações radicais da relação homem natureza, almeja-se que a educação ambiental desempenhe essa função, destacando a relevância em se observar seu caráter transversal no trabalho continuo e permanente entre áreas diversas do conhecimento, possibilitando novos objetos do saber, sendo, pois, a educação, indispensável para a humanidade. Dentro dessa abordagem, a crítica quanto à proibição de se criar disciplina específica para educação ambiental, tendo em vista o caráter ainda mais dificultador no que tange a eficiência. Outrossim, não retiraria o caráter de transversalidade da educação ambiental. Coaduna com tal premissa:

É verdade que a educação ambiental é temática transversal. Mas isso não significa que necessariamente se deva proibir a criação de disciplina específica. Sobretudo considerando-se a complexidade científica e técnica das questões ambientais e da gravidade do atual estágio de degradação ambiental e dos riscos ambientais. Nem todos os docentes estão aptos teórica, metodológica e pedagogicamente a trabalhar com os temas ambientais, em sala de aula ou em atividades complementares (STEINMETZ, 2009, p. 6). (grifo nosso).

Com fulcro nessa afirmativa, adota-se, pois, o perpetrado por Platão (427 a.C - 347 a.C), vez que o filósofo disseminava "a noção de que a educação é fundamental para os homens" (NAVES; REIS. 2016, p. 51), vindo a tornar um "paradigma para a posteridade" (NAVES; REIS. 2016, p. 51).

Nesse prisma, a concepção de Paideia, que se transfigura para além de um mero vocábulo grego, fazendo alusão à conceituação que se remete aos primórdios do pensamento educacional grego. Paideia refere-se, nessa seara, a um sistema educativo que se constituiu em teoria e modelo matriz da educação ocidental, que visava, em primazia, o treinamento do homem por completo, retirando qualquer característica de mero produtor. (GROSS, 2007). 
Jaeger (2001), ao referir-se à Paideia, aborda a educação como um processo contínuo, duradouro e que visa o bem, com base em Platão. Faz-se necessário trazer a discussão para os tempos modernos e realizar enquadramento para as necessidades reais, no que tange ao discurso antidemocrático de Platão e sua negativa à retórica argumentativa. Visa-se prender a atenção ao processo educativo de Platão, na concepção de Paideia, e com intuito de efetivar a educação ambiental, propiciando uma releitura concernente à ação educativa, nos quesitos pedagógicos.

Nesse viés, pauta-se, principalmente, em duas das características do denominado homem justo, segundo Platão (Jaeger, 2001), qual seja, a parte da alma racional (a razão) e a irascível (que não é razão ou desejo) que, por meio da educação (instrução), não se deixam dominar pela terceira parte, que é a apetitiva.

Em análise do que venha a ser a terceira parte da alma do homem justo/ideal, Naves e Reis aferem tratar-se da parte em que se deixa corromper pelos desejos, "a atração dos indivíduos pelo objeto" (NAVES; REIS, 2016, p. 53). Assim, com a devida instrução, a parte racional, auxiliada pela irascível, controla a apetitiva, ou seja, em analogia, a irracionalidade do homem em destruir o meio que o fornece a própria vida seria combatida, por meio da educação, ao compreender a necessidade da preservação.

Naves e Reis, ao abordar a respeito da obra "A república", explicitam a real compreensão do termo Paideia, destacando o quanto "a educação é fundamental para que cada parte da alma possa cumprir sua própria tarefa, o que torna a alma justa" (NAVES; REIS. 2016, p. 54) e, consequentemente, torna o homem mais justo. Lê-se, em Platão:

\footnotetext{
E essas duas partes, tendo sido assim educadas, verdadeiramente ensinadas e formadas para cumprir sua tarefa, governarão a concupiscência que, em cada um, é a parte maior da alma e, por natureza, é insaciável de riquezas. Ficarão de vigia para que ela não se encha dos chamados prazeres do corpo e, ao tornar-se maior e mais forte, deixe de cumprir sua tarefa e, embora isto não lhe caiba por sua natureza, tende a escravizar e governar as outras e subverta a vida de todas as pessoas. (PLATÃO, 2006, p. 168).
}

Insta salientar que a concepção de Paideia sofreu evolução conforme o tempo e a história, que passou do significado de criação de crianças, em Aischylos (525a.C - 456 a.C) a ênfase nos aspectos práticos da instrução, em Aristófanes (444a.C - 385a. C) e Tucídites 
(460a.C - 395a.C). Vindo, em Homero, conforme Jaeger (2001), referir-se ao código de nobreza cavalheiresca, com formação intelectual, física e virtuosa. Já com os sofistas, surge, conforme Gross (2007), o estudo da gramática, da retórica, da dialética e a transformação do conhecimento enciclopédico, visando a realização da vida prática. Com Demócrito (469a.C.370a.C.) Paideia assume caracterização de educação espiritual, tornando-se bem inalienável inerente a cada um.

E, no século IV, a.C, Sócrates e Platão, entre outros, aparecem com o novo conceito de Paideia, destinando à figura do filósofo a característica de modelo de homem, ou seja, um ser iluminado, vivente do mundo das ideias, com habilidades de instruir os demais homens a governar a cidade- Estado, como cidadão completo e, nesse sentido, como homem justo.

Em que pese a ideia original de Platão em destinar aos ilustrados o poder em formar o caráter dos subalternos, e estabelecer padrões de atividades a serem exercidas, não é esse o propósito em tê-lo como marco a ser observado na educação ambiental, como que a desconsiderar a epistemologia ambiental condizente à complexidade ambiental. Não se almeja privilegiar o processo educativo vertical, desconsiderando as variáveis que envolvem o contexto complexo, inviabilizando a comunicação, a alimentação e a retroalimentação na troca entre alunos, mestres e atores sociais, haja vista a não detenção do conhecimento pleno, segundo análise da complexidade ambiental (Leff, 2012).

Pretende-se tê-lo como precursor do processo educativo, como primeiro programa de educação da cultura ocidental, em que considera o processo educativo de suma relevância à humanidade, devendo ser continuado, permanente e completo. Ademais, tais preceitos corroboram com alguns princípios da educação ambiental, como o da continuidade e o da transdisciplinaridade ${ }^{4}$.

Outro ponto a questionar é que, quanto à efetividade da educação ambiental, já trazida ao debate, ao afirmar a ausência de pretensão em estabelecer um modelo padrão de comportamento pedagógico entre os educadores ambientais, parece estar contrário aos padrões platônicos. Entretanto, segundo Loureiro (2012), é preciso elevar os arquétipos das

\footnotetext{
${ }^{4}$ Tem-se que, no concernente às experiências transdisciplinares, segundo Reis e Carvalho, "1) a aproximação de diferentes disciplinas e áreas do conhecimento; 2) uso de metodologias unificadas criadas a partir de diferentes áreas do conhecimento; 3 ) preenchimento das áreas indefinidas do saber, gerando novas disciplinas ou servindo de trâmite entre as várias disciplinas, ficando aqui a área propriamente transdisciplinar. (REIS; CARVALHO. 2014, p. 13). Nesse prisma, transpassa a interdisciplinaridade e multidisciplinaridade, todos consubstanciados na concepção da fragmentação do saber.
} 
atitudes individuais para um patamar mais amplo, no sentido de globalizar as ações, considerando, evidentemente, todo o complexo histórico e social em que está inserido o público alvo do projeto educacional. Nesse diapasão:

\begin{abstract}
Em Educação Ambiental, a negação da homogeneidade simplificadora e o respeito à diferença de ideias e modos de viver são fundamentais e coerentes com a visão de ambiente enquanto complexidade do mundo. Porém, ao se defender o diverso não se pode cair num pluralismo indiferenciado, em que as vivências pessoais e as lutas sociais se deem numa historia diluída e desconexa, na qual a negação, a confrontação de teorias e argumentos e a superação transformadora tornam-se impossíveis de se realizarem. Isso seria recair num relativismo absoluto e no atomismo de iniciativas que passam a ser vistas como válidas em si mesmas, posturas que em nada favorecem a consolidação da educação como atividade cidadã, reflexiva [...] (LOUREIRO, 2012, p. 26).
\end{abstract}

Significa dizer que, não desmerecendo as atitudes individuais, é preciso envolvimento e comprometimento dos órgãos públicos na busca por uma educação ambiental realmente eficaz.

Sem qualquer tipo de negligência quanto às dificuldades existentes para implementação de políticas públicas destinadas a esse fim, considerando que, no que tange à educação formal, afirma-se a necessidade de um processo de execução um tanto quanto complexo, devido à necessidade de equipe multidisciplinar, com capacitação de profissional bem como das instituições.

Faz-se imprescindível sair da estagnação em que o homem se encontra enquanto ser pertencente ao meio. É preciso buscar por uma ética pautada em valores que se fazem ideais universais, ou, práticas universais em relação ao meio ambiente, em prol de não se ver esgotados os recursos naturais.

Aqui, mais uma vez apresenta-se a visão platônica, destacando-se a linha da ascensão do conhecimento, vez que "aquele que passa por todo o processo [...] através da razão, é o indivíduo que possui (atinge) os verdadeiros valores, por isso ético.” (NAVES; REIS, 2006, p. $67)$.

Dessa forma, o homem que passa pelo processo adequado de educação, desenvolve a capacidade de ascender o conhecimento, vislumbrando a realidade que é a causa dos fatos. Em analogia, com uma educação ambiental verdadeiramente adequada, completa e eficaz, é 
possível ocorrer uma modificação de comportamento, no sentido de se preservar o meio ambiente, que se vê em vias de esgotabilidade de seus recursos.

Nessa seara, a necessidade de releitura da ação educativa presente no contexto da educação ambiental. Retirar os princípios inerentes a ela do plano de propósitos e, em junção ao disseminado por Platão, trazer, à discussão, a primazia da ação educativa e todas as benesses possíveis de ocorrer.

Contudo, nas basta, ainda, observar o processo platônico, condizente à continuidade e multidisciplinaridade, é preciso, também, segundo Loureiro (2012) focar no pilar socioambiental, considerar as desigualdades sociais, os movimentos econômicos, a realidade como um todo, pois, afinal, "afirmar que a vida física e espiritual do homem e a natureza são interdependentes significa apenas que a natureza se inter-relaciona consigo mesma, já que o homem é uma parte da natureza." (MARX, apud LOUREIRO, 2012, p. 10). Daí, a transversalidade de objetos no estudo da educação ambiental.

Faz-se nítida e clara a junção dos preceitos de Leff (2012) e Loureiro (2012) referente à abordagem de quebrar barreiras aos modelos dominantes e buscar desenvolver programas curriculares mais condizentes com toda a construção do saber ambiental, que se consubstancia em seu caráter transversal. Trata-se, pois, da necessidade de uma epistemologia ambiental, voltada para o saber ambiental, que advém de toda uma complexidade e, nesse sentido, está, mais uma vez, a questão da transdisciplinaridade, inserida na abordagem da (des) fragmentação do saber, em vias de rebater a racionalidade puramente econômica. Corrobora com o apresentado:

\footnotetext{
A epistemologia ambiental não busca a formalização de um método desenhado para integrar e recompor o conhecimento no mundo moderno, racionalizado e globalizado em que habitamos. O saber ambiental, que nasce no campo de externalidade das ciências, penetra os interstícios dos paradigmas do conhecimento a partir de diferentes perspectivas, lança novos olhares e vai eliminando certezas, abrindo os raciocínios fechados que projetam o ambiente para fora das órbitas celestiais dos círculos das ciências. (LEFF, 2012, p. 19).
}

Tanto da análise da abordagem platônica de Jaeger (2001), referente à concepção de Paideia, quanto da visão de Loureiro (2012), bem como no que tange ao trazido por Leff (2012), depreende-se a relevância da necessidade de se alterar os padrões educativos voltados para o meio ambiente. 
Assim, Loureiro (2012) chama atenção para o perigo de se esvaziar a responsabilidade também do terreno da ação política. É preciso, sim, uma ética ambiental, mas não se pode voltar-se somente para a questão ambiental, pautando-se em valores universais (ideais universais), em verdades únicas, em objetivos moralistas. Lê-se:

Não há mudança ética possível quando se ignora a sociedade em que se move, porque os valores não são um simples reflexo da estrutura econômica, mas são definidos a partir de condições históricas específicas, inseridas num movimento dialético de mútua constituição entre objetividade e subjetividade. (LOUREIRO, 2012, p. 15). (grifo nosso).

A dialética na lógica da educação ambiental, confrontando os pilares inerentes ao conceito de desenvolvimento sustentável, especialmente, o ambiental, o econômico e o social, transcende à responsabilização puramente ética, tendo em vista não ser o homem um ser pacífico, inerte ao tempo, à história, à cultura, pois o homem é o construtor da sua própria história. Nesse diapasão, a epistemologia ambiental engloba saberes e novos saberes, realidades desconsideradas e ocultas, momentos históricos e perspectivas culturais e, nesse viés, a continuidade e perpetuação do processo educativo de Platão, aqui, em uma equivalência ao eterno desconhecimento do saber.

Se todos esses elementos também já foram considerados na concepção de Paideia (Jaeger, 2001), evidencia-se a lógica da continuidade de sua observação para a plenitude da educação ambiental. Inequívoca a junção da ação à reflexão. Nessa ceara, entende-se Loureiro (2012), somente com o comprometimento de todos, no sentido de mudança cultural e social, é que se vislumbra a construção de sociedades ecologicamente equilibrada e justa, com uma alteração de valores. E, se faz possível uma alteração de valores com a busca contínua pelo aprimoramento por meio da educação, pelo busca do saber, do conhecer.

Assim, a mudança ética envolvida no movimento moral, torna-se viável com a consideração do sistema em que a sociedade impera, devendo ser, sem sombra de dúvida, matéria de educação ambiental. Plausível, dentro dessa perspectiva, ponderar que a Paideia platônica (trazida por Jaeger -2001), de extinguir o relativismo moral, na ideia do bem, é condizente à busca pelas causas e pelo remediar das desigualdades socioambientais e, 
estudando-as, se estará em busca pelo bem, pelo bem da vida, pelo bem do meio ambiente ecologicamente equilibrado (Costa, 2010).

Faz-se, assim, supremo observar a complexidade ambiental:

\begin{abstract}
Refletir sobre a complexidade ambiental abre uma estimulante oportunidade para compreender a gestação de novos atores sociais que se mobilizam para a apropriação da natureza, para um processo educativo articulado e compromissado com a sustentabilidade e a participação, apoiado numa lógica que privilegia o diálogo e a interdependência de diferentes áreas de saber. Mas também questiona valores e premissas que norteiam as práticas sociais prevalecentes, implicando mudança na forma de pensar e transformação no conhecimento e nas práticas educativas (JACOBI, 2003, p. 191).
\end{abstract}

Nesse sentido, e extremamente bem aludido, o desafio maior da educação ambiental "é estimular mudanças de atitude e de comportamento nas populações, vez que as capacidades intelectuais, morais e culturais do homem permitem que as responsabilidades para com outros seres vivos e para com a natureza sejam respeitadas." (ROGÉRIO; NISHIJIMAP, 2015, p. 248).

O cerne da proposta presente nesse artigo tange na ênfase da necessidade em buscar a essência da Paideia, no quesito educação continuada, permanente, aperfeiçoada, e, também disciplinada, sem, necessariamente, referir-se a um método formalizado, que associe aspectos éticos maiores e que considere a complexidade ambiental.

Segundo Leff (2003), a partir do pensamento complexo, vislumbra-se dimensão transformadora e emancipatória do ambientalismo e, consequentemente, da educação ambiental. Tem-se que tais dimensões deveriam ser inerentes ao ensino jurídico, tendo em vista, como já aludido, que o direito não é eficaz em sua visão meramente punitiva, procurando atuar como estímulo para práticas que viabilizem modificar a realidade (Alves e Machado, 2016). Equivale a observação do contexto, do todo e, corrobora com tal assertiva a afirmação de que não é mais possível adotar reducionismos, posto que "problemas ambientais se originam de práticas sociais equivocadas que estão a exigir posturas que visem, além da mudança cultural e comportamental necessárias, uma transformação social" (ENCARNAÇÃO, 2008, online).

Loureiro (2012) também comunga dessa teoria ao destacar a importância de se analisar e estudar as causas das desigualdades sociais, no âmbito da educação ambiental, 
buscando meios de minimizar as diferenças, que se enquadra na denominada hermenêutica ambiental, proposta por Leff (2007):

\begin{abstract}
A hermenêutica ambiental não constitui uma exegese de textos em busca dos precursores do saber ambiental, e sim um olhar que assume a perspectiva da complexidade ambiental - entendida como expressão da crise civilizatória -, a partir da qual se desenraizam as origens e as causas desta crise, e a partir da qual se projeta um pensamento (da complexidade) orientado no sentido da reconstrução do mundo. A hermenêutica abre os sentidos bloqueados pelo hermetismo da razão. (LEFF, 2007, p. 192).
\end{abstract}

Outro ponto relevante a observar tange nos obstáculos decorrentes da adoção das premissas cartesianas utilizadas nos métodos educacionais explicativos, que viabilizam esquecimentos da matéria transmitida "sem ter aprendido e retido o mais importante: os valores de uma ética que considera o ambiente enquanto algo necessário e inegável em nossas vidas." (AVZARADEL, 2014, p. 163). Isso se faz devido critérios de repasse do conteúdo das disciplinas sem a preocupação em desenvolver nos alunos consciência crítica, premissa de suma relevância, em especial nos cursos jurídicos, em que urge a necessidade de sair da inércia quanto ao ensino puramente dogmático. Segundo essa premissa:

\footnotetext{
Em sua função controladora (diretiva), o Direito necessita ditar o ritmo social, porém, na Academia, os discentes precisam ser estimulados para práticas que modifiquem uma realidade de passividade e de suposto controle a partir da premissa dogmática, visando a produção de um ser crítico e em condições de pensar o direito numa dimensão para além do direito posto. (ALVES; MACHADO, 2016, p. 72)
}

Não há como adotar um ou outro sistema negligenciando os tempos atuais. Se para disseminar a necessidade em se preservar o meio ambiente, com a participação inerente dos cidadãos, se fizer necessário um híbrido sistema educativo, em que desenvolva uma ação educativa mais eficaz, que assim ocorra, plenipotencializada por ações públicas, conforme estabelecido na CRFB/1988.

\title{
5 CONSIDERAÇÕES FINAIS
}


Não se fazem mais necessárias discussões apenas quanto ao estado de devastação do meio ambiente e, tão pouco, da urgente necessidade em buscar mecanismos que culminem no real desenvolvimento sustentável, com a preservação da natureza.

Os meios para disseminar essa necessidade é que ainda são objetos de análise, tendo em vista as dificuldades no que tange à efetivação da informação, mais especificamente, concernente à educação ambiental.

A educação ambiental é, pois, um instrumento hábil para disseminar a necessidade em se preservar o meio ambiente alertando a sociedade dos riscos em, num futuro não muito distante, vê-se esgotados os recursos naturais e, consequentemente, extinguir a própria espécie humana, tendo em vista, a característica de pertença do homem ao meio.

Em que pese a educação ambiental não ser direito fundamental consagrado na CRFB/1988, é princípio e, apresenta extrema relevância no ordenamento jurídico pátrio. Ademais, encontra-se vinculado ao direito fundamental da educação e é instrumento de alcance do direito fundamental ao meio ambiente ecologicamente equilibrado, além de se encontrar intimamente ligado aos princípios da informação e da participação, devendo receber ênfase no ensino e pesquisa jurídicos, diante entrelaçamentos oriundos da concepção de cidadania.

Ainda nessa seara, pelo fato de se tratar de norma jurídica, independentemente de se referir a uma norma programática, sua eficácia jurídica é inquestionável, sendo quesito suficiente para exigir sua aplicabilidade junto ao Poder Judiciário, ou seja, transformar planos em ações tangíveis.

Entretanto, é notória a necessidade de uma releitura da ação educativa consubstanciada na educação ambiental, para além do argumento de negligência do Poder Público quanto às Políticas Públicas. É preciso um agir educativo que considere a complexidade ambiental, que se paute na concepção trazida pela Paideia platônica em seus quesitos de educação continuada, permanente, aperfeiçoada, completa, e que associe aspectos éticos maiores, em prol de ideais universais concernentes a mudanças comportamentais.

De suma relevância considerar, dentro do processo educativo, as realidades ocultas, os novos saberes, as contingências e, se o que se visa alcançar é, de fato, desenvolvimento sustentável, é preciso destinar foco também para os pilares econômicos e sociais, para além do ambiental, em toda a abordagem da educação ambiental.

Revista de Pesquisa e Educação Jurídica | e-ISSN: 2525-9636 | Brasília | v. 3 | n. 1 | p. 22-43 | Jan/Jul. 2017. 
Ação educativa eficaz reúne, em seus propósitos, um conjunto de ações individuais, agindo os cidadãos como agentes multiplicadores, como atores sociais, referenciando-se em ações políticas dentro da perspectiva de mudanças emancipatórias. Contudo, tais atitudes individuais, a título de se plenipotencializar os resultados advindos da educação ambiental, devem estar atreladas a políticas públicas e, se para isso se fizer necessário um híbrido sistema educativo, unificando teorias, será positivamente considerado, tendo em vista o escopo maior, qual seja, disseminar a necessidade em se preservar o meio ambiente e, consequentemente, a mantença da própria espécie humana.

\section{REFERÊNCIAS}

ALVES, José Maria Eiró; MACHADO, Fabiola Villela. Crítica ao Ensino Jurídico à luz da Teoria Crítica: um breve panorama da transição do século XX para o século XXI. In. V ENCONTRO DE INTERNACIONALIZAÇÃO DO CONPEDI MONTEVIDÉU URUGUAI. INSTITUCIONES Y DESARROLLO EN LA HORA ACTUAL DE AMÉRICA LATINA, 2016, URUGUAI. : Prof. Dr. Carlos André Birnfeld, Dra. Ema Beatriz Farias Martínez, Dr. Horácio Wanderlei Rodrigues (Orgs.). Anais Montevidéu/Uruguai: Conselho Nacional de Pesquisa e Pós-graduação em Direito (CONPEDI). 2016, p. 57-73. Disponível: www.conpedi.org.br em publicações. Acesso: 2 Mai 2017.

AVZARADEL, Pedro Curvello Saavedra. Reflexões soobre ética ambiental e educação ambiental. In: CARLI, Ana Alice de; MARTINS, Saadia Borba. Educação ambiental: premissa inafastável ao desenvolvimento econômico sustentável. Rio de Janeiro: Lumen Juris, 2014.

BARRETO, Leandro de Marzo; MACHADO, Paulo Affonso Leme. A construção do diálogo e da solidariedade e a proteção do bem ambiental e da natureza na concepção universal do humano, a partir de uma leitura da Encíclica Laudato Si. Revista Veredas do Direito, Belo Horizonte, v.13 .n.26. p.319-336 . Maio/Agosto de 2016. Disponível:

http://www.domhelder.edu.br/mestrado. Acesso: 06 nov 2016.

BRASIL. Lei $n^{\circ}$ 6.938, de 31 de agos de 1981. Dispõe sobre a Política Nacional do Meio Ambiente, seus fins e mecanismos de formulação e aplicação, e dá outras providências. Diário Oficial, Brasília, 2 set. 1981. Disponível: http://www.planalto.gov.br/ccivil_03/decreto/2002/D4281.hm. Acesso: 20 mar. 2017. Constituição da República Federativa do Brasil de 1988. Diário Oficial da União, Brasília, 05 out. 1988. 
Lei $n^{0}$ 9.795, de 27 abr. 1999. Dispõe sobre a educação ambiental, institui a Política Nacional de Educação Ambiental e dá outras providências. Diário Oficial, Brasília, 28 abr. 1999. Disponível:

http://www.planalto.gov.br/ccivil_03/decreto/2002/D4281.htm. Acesso: 20 mar. 2017.

Decreto-lei $n^{\circ} 4.281$, de 25 jun. 2002. Regulamenta a Lei no 9.795, de 27 de abril de 1999, que institui a Política Nacional de Educação Ambiental, e dá outras providências. Diário Oficial, Brasília, 26 jul. 2002. Disponível: http://www.planalto.gov.br/ccivil_03/decreto/2002/D4281.htm. Acesso: 20 set. 2016.

Ministério do Meio Ambiente. Disponível:

http://www.mma.gov.br/educacao-ambiental. Acesso: 14 mai 2016.

COSTA, Beatriz Souza, Meio Ambiente como direito à vida- Brasil, Portugal, Espanha. Belo Horizonte: o Lutador, 2010.

ENCARNAÇÃO, Fátima Luvielmo. Complexidade e educação ambiental. Revista Espaço Acadêmico. Dezembro de 2008, ano VIII. Disponível: https://www.espacoacademico.com.br/091/91encarnacao.htm. Acessado: 20 mar 2017

FURLAN, Alessandra Cristina et al. Educação Ambiental para o Desenvolvimento Sustentável.UNOPAR Cient., Ciênc. Juríd. Empres., Londrina, v. 11, n. 2, p. 87-94, Set. 2010. Disponível:

http://www.pgsskroton.com.br/seer/index.php/juridicas/article/viewFile/959/921. Acesso: 13 mai 2016.

GOMES, Magno Federici. Direito educacional superior: evolução, legislação, procedimentos administrativos e função normativa. Curitiba: Juruá, 2012.

GROSS, R.. Paidéia: educação e pedagogia. In: VII Congresso Nacional de Educação, 2007, Curitiba. VII congresso Nacional de Educação- EDUCERE-SABERES DOCENTES. Curitiba, Pr: PucPr, 2007. p. 114-121. Disponível:

http://cienciaparaeducacao.org/publicacao/gross-r-paideia-educacao-e-pedagogia-in-viicongresso-nacional-de-educacao-2007-curitiba-vii-congresso-nacional-de-educacao-educeresaberes-docentes-curitiba-pr-pucpr-2007-p-114-121/. Acesso: 8 abr 2017

JACOBI, Pedro. Educação Ambiental, cidadania e Sustentabilidade. Cadernos de Pesquisa, n. 118, março/ 2003, pp.189-205. Disponível:

http://www.scielo.br/pdf/cp/n118/16834.pdf. Acesso: 21 abr. 2016.

JAEGER, Werner. Paideia: a formação do homem grego. Tradução: Artur M. Parreira. 4 ed. São Paulo: Martins Fonseca, 2001

LEFF, Enrique. Saber Ambiental: Sustentabilidade, Racionalidade, Complexidade, Poder. Petrópolis: Vozes, 2001.

A complexidade ambiental. Traduzido por Eliete Wolff. São Paulo: Cortez, 2003.

Revista de Pesquisa e Educação Jurídica | e-ISSN: 2525-9636 | Brasília | v. 3 | n. 1 | p. 22-43 | Jan/Jul. 2017. 
Epistemologia Ambiental. São Paulo: Cortez, 2007.

Aventuras da epistemologia ambiental: da articulação das ciências ao diálogo dos saberes. Tradução: Silvana Cobucci Leite. São Paulo: Cortez, 2012.

LEITE, Ana Lúcia Tostes de Aquino; MEDINA, Naná Mininni (Coord.). Educação ambiental; curso básico a distância: documentos e legislação da educação ambiental. 2. ed. Brasília: MMA, 2001. v. 5.

LOUREIRO, Carlos Frederico Bernardo. Trajetória e fundamentos da educação ambiental. 4. ed. São Paulo: Cortez, 2012.

NAVES, Bruno Torquato de Oliveira; REIS, Émilien Vilas Boas. Bioética Ambiental: premissas para o diálogo entre ética, a bioética, o biodireito e o direito ambiental. 1 ed. Rio de Janeiro: Lumen Juris, 2016.

PLATÃO. A república. Tradução de Anna Lia Amaral de Almeida Prado. São Paulo: Martins Fontes, 2006.

REIS, Émilien Vilas Boas; CARVALHO, Nara Pereira. Transdisciplinaridade e a cidade. In: RIOS, Mariza; CARVALHO, Newton Teixeira; KLEINRATH, Stella de Moura. A cidade real e a cidade ideal; em uma reflexão transdisciplinar. Belo Horizonte: Del Rey, 2014. Cap. I, p. 7-47.

ROGÉRIO, Marcele Scapin; NISHIJIMA Toshio. O direito ao meio ambiente sustentável por meio da educação ambiental voltada ao uso racional da propriedade rural e ao cumprimento da sua função social. Revista Veredas do Direito, Belo Horizonte, ?? v.12 ? n.23 ? p.235-258 Janeiro/Junho de 2015. Disponível: http://www.domhelder.edu.br/mestrado. Acesso: 18 Nov 2016.

SAMPAIO, José Adércio Leite; WOLD, Chris; NARDY, Afrânio. Princípio de Direito Ambiental - na dimensão internacional e comparada. Belo Horizonte: Del Rey, 2003.

SARLET, Ingo Wolfgang. A eficácia dos direitos fundamentais: uma teoria geral dos direitos fundamentais na perspectiva constitucional. 11. ed. Porto Alegre: Livraria do Advogado, 2012.

SARLET, Ingo Wolfgang; FENSTERSEIFER, Tiago. Direito Constitucional ambiental estudos sobre a Constituição, os Direitos Fundamentais e a Proteção do Ambiente. São Paulo: Revista dos Tribunais, 2011.

STEINMETZ, Wilson. Educação ambiental, Constituição e legislação: análise jurídica e avaliação crítica após dez anos de vigência da Lei 9.795/1999. Revista de Direito ambiental, São Paulo, v. 15, nº 55, p. 189-202, jul./set. 2009.

Revista de Pesquisa e Educação Jurídica | e-ISSN: 2525-9636 | Brasília | v. 3 | n. 1 | p. 22-43 | Jan/Jul. 2017. 